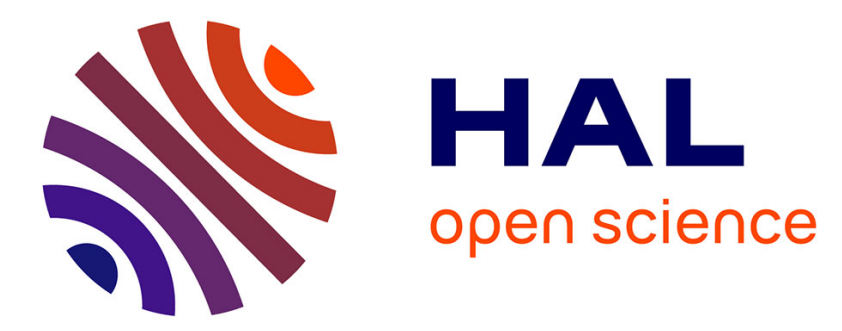

\title{
Design of Electrically Conductive Structural Composites by Modulating Aligned CVD-Grown Carbon Nanotube Length on Glass Fibers
}

Delong He, Benhui Fan, Hang Zhao, Xiaoxin Lu, Minhao Yang, Yu Liu, Jinbo Bai

\section{To cite this version:}

Delong He, Benhui Fan, Hang Zhao, Xiaoxin Lu, Minhao Yang, et al.. Design of Electrically Conductive Structural Composites by Modulating Aligned CVD-Grown Carbon Nanotube Length on Glass Fibers. ACS Applied Materials \& Interfaces, 2017, 9 (3), pp.2948 - 2958. 10.1021/acsami.6b13397. hal-01842499

\section{HAL Id: hal-01842499 \\ https://hal.science/hal-01842499}

Submitted on 12 Mar 2020

HAL is a multi-disciplinary open access archive for the deposit and dissemination of scientific research documents, whether they are published or not. The documents may come from teaching and research institutions in France or abroad, or from public or private research centers.
L'archive ouverte pluridisciplinaire HAL, est destinée au dépôt et à la diffusion de documents scientifiques de niveau recherche, publiés ou non, émanant des établissements d'enseignement et de recherche français ou étrangers, des laboratoires publics ou privés. 


\section{Design of Electrically Conductive Structural Composites by Modulating Aligned CVD-Grown Carbon Nanotube Length on Glass Fibers}

Delong He, Benhui Fan, Hang Zhao, Xiaoxin Lu, Minhao Yang, Yu Liu, Jinbo Bai*

Laboratoire Mécanique des Sols, Structures et Matériaux (MSSMat), CNRS UMR

8579, Ecole CentraleSupelec, Université Paris-Saclay, Grande Voie des Vignes, 92290, Chatenay-Malabry, France

\section{* Corresponding author:}

Dr. Jinbo Bai, Email: jinbo.bai@centralesupelec.fr. Phone: +33 (0)1 41131316. Fax: +33(0)1 41131460 .

KEYWORDS: Carbon nanotubes, Glass fiber, Chemical vapor deposition, Structural composites, Electrical conductivity, Interfacial/Interphase 


\section{ABSTRACT}

Function-integration in glass fiber (GF) reinforced polymer composites is highly desired for developing light-weight structures and devices with improved performance and structural health monitoring. In this study, homogeneously aligned carbon nanotube (CNT) shell was in-situ grafted on GF by chemical vapor deposition (CVD). It was demonstrated that the CNT shell thickness and weight fraction can be modulated by controlling the CVD conditions. The obtained hierarchical CNTs-GF/epoxy composites show highly improved electrical conductivity and thermo-mechanical \& flexural properties. The composite through-plane and in-plane electrical conductivities increase from a quasi-isolator value to $\sim 3.5$ and $100 \mathrm{~S} / \mathrm{m}$, respectively, when the weight fraction of CNTs grafted on GF fabric varies from 0 to $7 \%$, respectively. Meanwhile, the composite storage modulus and flexural modulus and strength improve as high as $12 \%, 21 \%$ and $26 \%$, respectively, with $100 \%$ retention of the glass transition temperature. The reinforcing mechanisms are investigated by analyzing the composite microstructure and the interfacial adhesion and wetting properties of CNTs-GF hybrids. Moreover, the specific damage-related resistance variation characteristics could be employed to in-situ monitor the structural health state of the composites. The outstanding electrical and structural properties of the CNTs-GF composites were due to the specific interfacial and interphase structures created by homogeneously grafting aligned CNTs on each GF of the fabric. 


\section{Introduction}

Glass fiber reinforced polymer composites (GFRPs) are extensively used in the fields of aeronautics and aerospace, automotive, new energy, construction and industrial infrastructures. This is due to their high specific stiffness and strength, high corrosion resistance, excellent fatigue behavior and low cost. ${ }^{1,2}$ Functionalization of GFRPs can further improve structure performance and extend their applications in electrostatic dissipation, electromagnetic shielding and absorption, and structure health monitoring, etc. ${ }^{3-5}$ However, it is still quite difficult to develop electrically conductive GFRPs with adjustable high conductivity while retaining their intrinsic structural properties. This requires constructing efficient electron conduction network in isolating polymer bulk matrix, while guaranteeing load transfer between reinforcement fibers and matrix.

Traditionally, electrically conductive GFRPs are produced by either adding conductive particles like carbon blacks and metal particles in polymer matrix, or coating metallic meshes or conductive paints on the surface. ${ }^{6,7}$ These methods have several disadvantages, such as low reinforcing efficiency, weight gain, mismatch of thermal expansion coefficients, and interfacial corrosion. Instead, incorporation of conductive nanofillers such as carbon nanotubes (CNTs) in the polymer matrix has been considered as one of the most promising solutions to realize multifunctional GFRPs. ${ }^{3,8-12}$ This is mainly due to CNT's specific structure and extraordinary mechanical, electrical and thermal properties. ${ }^{13}$ Meanwhile, CNTs-based hybrid structures (CNTs-GNP, CNTs- $\mathrm{Al}_{2} \mathrm{O}_{3}$, etc.) have also been added in polymer matrix to 
produce electrically conductive GFRPs. ${ }^{14,15}$ Nevertheless, strong agglomeration tendency of CNTs makes them particularly difficult to be homogeneously dispersed in polymer matrices. The addition of CNTs unavoidably causes resin viscosity increase, and deteriorates the ease of processing. This greatly restricts resin impregnation of fibers, resulting in defects in final composites.

Alternatively, electrically conductive GF fibers can be developed by coating CNTs. It has been reported that CNTs-coated GFs exhibit electrical conductivity, piezoresistivity and improved interfacial properties. ${ }^{16-23}$ Some studies have also demonstrated their potential applications in structural health monitoring, electromagnetic absorption and shielding, in-situ cure monitoring, thermal energy harvesting. ${ }^{21-28}$ Several techniques have been reported to develop CNTs-coated GF, which include the solution coating methods such as dip coating, spray coating and electrophoretic deposition, and chemical vapor deposition (CVD) $\cdot{ }^{27-34}$ For the solution deposition techniques, it is a prerequisite to have homogeneous and stable CNT suspension. In general, some chemical surfactants or polymers are employed during CNT dispersion process due to their inert surface characteristics. However, these additives have low mechanical properties and low thermal stability. Thus, the removal processes are needed after CNT coating, which might be time-consuming and generate fiber degradation. Otherwise, functionalized CNTs can be directly dispersed in a solvent. And the coating processes could be potentially scaled-up via a roll-to roll process which allows obtaining a conductive layer on glass fibers. ${ }^{12,35}$ However, the control on the alignment of CNTs on glass fibers is difficult to be realized. 
Direct growth of CNTs on GF by CVD can be realized using one step procedure. ${ }^{30}$ A continuous growth process could be used for scaled-up production of CNTs-grafted GFs and multifunctional composites. However, the reported CVD-synthesized CNTs-GF always have CNTs which are not homogeneously grown on the whole fiber surface, and often in entangled state. ${ }^{25}$ Very few investigations have been reported so far on the control of the length, density and organization of CNTs grafted on GF. In consequence, the influence of these factors on the hierarchical composite properties has not yet been fully understood. Thus, it is highly desired to achieve homogeneous CNT growth on glass fiber and to control CNT alignment in the polymer matrix.

In this study, aligned CNTs are homogenously synthesized on GF by CVD, forming a "scaffold-shell" CNTs-GF hybrid structure. The grafted CNT mass fraction (length and areal number density) can be modulated by varying the CVD conditions. A detailed investigation is also conducted on the influence of as-produced CNTs-GF hybrids on the composite electrical conductivity, thermo-mechanical properties and flexural properties, as well as their reinforcing mechanisms. This study may provide an insight into designing multifunctional GFRPs by modulating CNT geometry according to as-required demands, and promote GFRP applications in structural health monitoring, electromagnetic shielding and absorption, lightning strike, de-icing, etc.

\section{Experimental}

2.1 In-situ grafting of CNTs on GF by CVD 
The growth of CNTs was carried out by CVD in a quartz tube with a diameter of $100 \mathrm{~mm}$, which was heated by an electrical resistance furnace (CARBOLITE $\left.{ }^{\circledR}\right)$. The substrate was a S2 grade 6/1 twill glass fiber tissue, in which each warp and weft yarn contains 200 filaments of around $9 \mu \mathrm{m}$ in diameter. A tissue band $(300 \mathrm{~mm}$ in length $\times 6.5 \mathrm{~mm}$ in width) was supported on a quartz plate $(30 \mathrm{~mm}$ in width $\times 500 \mathrm{~mm}$ in length) placed in the center of tube. The furnace was heated up to $550-630^{\circ} \mathrm{C}$ in the presence of argon and hydrogen with a flow rate of 1.2 and $0.3 \mathrm{~L} \mathrm{~min}^{-1}$, respectively. After 10 min's temperature stabilization, a xylene solution containing $0.1 \mathrm{~g} \mathrm{ml}^{-1}$ ferrocene was injected into the reactor by a syringe injector $\left(\mathrm{RAZEL}^{\circledR}\right)$. The injection speed used was $24 \mathrm{ml} \mathrm{h}^{-1}$. At the same time, the second carbon source-acetylene gas was also fed at a flow rate of $0.3 \mathrm{~L} \mathrm{~min}^{-1}$. The growth lasted 3 to $10 \mathrm{~min}$ for different quantities of CNTs grafted on the glass fibers. The furnace was finally cooled down to room temperature under argon protective atmosphere $\left(1 \mathrm{~L} \mathrm{~min}^{-1}\right)$.

\subsection{CNTs-GF/epoxy composite preparation}

The composites were prepared using a high performance epoxy resin 1080S (Resoltech, France) and a curing agent 1084 (Resoltech, France). The 1080S/1084 (100:33 in weight) resin mixture was first mechanically stirred for $10 \mathrm{~min}$, and then degassed at room temperature for $30 \mathrm{~min}$ in a vacuum oven. The obtained mixture was uniformly spread over each GF or CNT-GF tissue until the latter was completely immersed. The six plies of GF or CNT-GF tissue were layered-up by hand along the same wrap orientation, and put into a vacuum bag which maintained a constant pressure of -0.5 bar by a mechanical pump. The curing process was conducted using 
a hot press. The temperature was first heated up to $60{ }^{\circ} \mathrm{C}$ at a rate of $2{ }^{\circ} \mathrm{C} \min ^{-1}$ under -0.5 bar, and then hold for 2 hours under 0.7 MP. Then, the airbag was quickly moved into an oven preheated to $60^{\circ} \mathrm{C}$ for another 15 hours under atmosphere condition. The as-prepared laminates were cut into different sizes for further microstructure characterizations and property tests.

\subsection{Structural and property characterizations}

Thermo-gravimetric analysis (TGA, NETZSCH STA 449 F3) was used to evaluate the mass fraction of CNTs grafted on the surface of GF tissue. The chopped CNTs-GF powders of around $80 \mathrm{mg}$ were heated from 30 to $900{ }^{\circ} \mathrm{C}$ at a rate of $10{ }^{\circ} \mathrm{C} \mathrm{min}{ }^{-1}$. The atmosphere used was a mixture of oxygen and nitrogen, whose flow rate was $20 \mathrm{ml}$ $\min ^{-1}$.

High resolution scanning electron microscopy (SEM, LEO 1530 Gemini) was conducted to characterize CNTs-GF morphology and composite microstructure. The cross-section of the sample before and after fractured in liquid nitrogen was characterized for each kind of composites obtained. The interesting surfaces were metallized in order to increase their electron conductivity.

Transmission electron microscopy (TEM, JEOL 1200 EX, and TITAN ${ }^{3}$ G2) and Raman spectroscopy (Jobin Yvon) were used to characterize the structures and distribution of CNTs on glass fibers. For the TEM investigation, the as-grown CNTs-GF was cut into short ones, and dispersed into ethanol solution by ultra-sonication (VWR USC500D) for 10 seconds at room temperature. A TEM copper grid was carefully dipped into the obtained suspension with tweezers in order 
to collect some CNTs-GF. When the grid was dried in air, it was putted on a specimen support for TEM characterization.

The in-plane and through-plane electrical conductivities of as-prepared CNTs-GF reinforced epoxy composites containing varied CNT mass fractions ( $\left.w t_{\mathrm{CNT}}\right)$ were measured using a voltage-current meter (Keithley 2400) using a two-probe method. The sample size used was about $10 \mathrm{~mm}$ (length) $\times 10 \mathrm{~mm}$ (width) $\times 1 \mathrm{~mm}$ (thickness) The opposite surfaces of each specimen were coated with conductive silver paint in order to decrease the contact resistance between the electrodes and sample surfaces.

The thermo-mechanical properties of the composites were also investigated by dynamic mechanical analysis (DMA, NETZSCH 242C) under three-point-bending mode. The characterizations were carried out at a frequency of $1 \mathrm{~Hz}$, and the temperature was varied from 30 to $200{ }^{\circ} \mathrm{C}$ at a heating rate of $3{ }^{\circ} \mathrm{C} \mathrm{min}{ }^{-1}$. The span length used was $40 \mathrm{~mm}$, and the sample size was $60 \mathrm{~mm}$ in length and $11 \mathrm{~mm}$ in width.

The mechanical properties of the as-prepared composites were investigated using a universal machine (Instron 5544) with a $2 \mathrm{kN}$ load cell. The flexural properties were measured under three-point bending mode at a span length of $25.4 \mathrm{~mm}$ and a cross head speed of $1 \mathrm{~mm} \mathrm{~min}^{-1}$, according to ASTM D2344 standard. The sample size used was around $60 \mathrm{~mm} \times 12.7 \mathrm{~mm} \times 1 \mathrm{~mm}$. For each CNT mass fraction composite, at least three samples were tested. Two extremities of each specimen were covered by silver paint and connected firmly with two metal electrode wires by super glue scotch. The latters were connected with the Keithley meter, which was used to record the 
electrical resistance variation during the flexural tests by data acquisition software LabView.

Single fiber tensile test, single bundle test and single fiber fragmentation test were carried out using the instrument-Instron 5544 with a load cell of $5 \mathrm{~N}$ and $2 \mathrm{kN}$, respectively. The single fiber tensile test was conducted according to NF ISO 11566. The cross-head speed used was $0.5 \mathrm{~mm} \mathrm{~min}^{-1}$ and the gauge length was about $25 \mathrm{~mm}$. The single fiber bundle tensile tests were done at the same cross-head displacement speed, using a gauge length of $50 \mathrm{~mm}$. The single fiber fragmentation test was carried out with the dog-bone shape samples of $0.2 \mathrm{~mm}$ in thickness and $10 \mathrm{~mm}$ in gauge length. Each individual GF or CNTs-GF was embedded in the middle of the composite specimen. Here, WWA/WWB4 (100:40 by weight) epoxy from Resoltech France was used for its large elongation ratio. The cross-head displacement was 0.1 $\mathrm{mm} \mathrm{min}^{-1}$. After fiber break saturation, the number of breaks was accounted using an optical microscope (Leica Aristomet DC300).

\section{Results and discussion}

\subsection{In-situ growth of homogeneously aligned CNTs on GF surface}

The in-situ growth of homogeneous CNTs on the glass fiber tissue was achieved by a one-step CVD method using metallorganic compound ferrocene as catalyst precursor. For example, as shown in Fig. 1a the color of as-received GF tissue turned from white to black after the growth of 2 wt. \% CNTs. SEM image shows that nanotubes grew perpendicularly and homogeneously on the whole surface of tissue (Fig. 1b). Each GF was covered by a continuous cylindrical shell consisting of 
radically aligned nanotubes. TEM images (Fig. 1c and d) conform that as-grown CNTs do organize in an aligned way. They perpendicularly distribute on the GF surface, instead of randomly entangling together. The nanotube has a length of around $2.5 \mu \mathrm{m}$ when $w t_{\mathrm{CNT}}=2 \%$, and its diameter varies between 10 and $20 \mathrm{~nm}$. Such well-aligned nanotubes may facilitate polymer resin diffusion by capillary force during composite fabrication, ${ }^{36,37}$ which guarantees high quality of cured laminate.
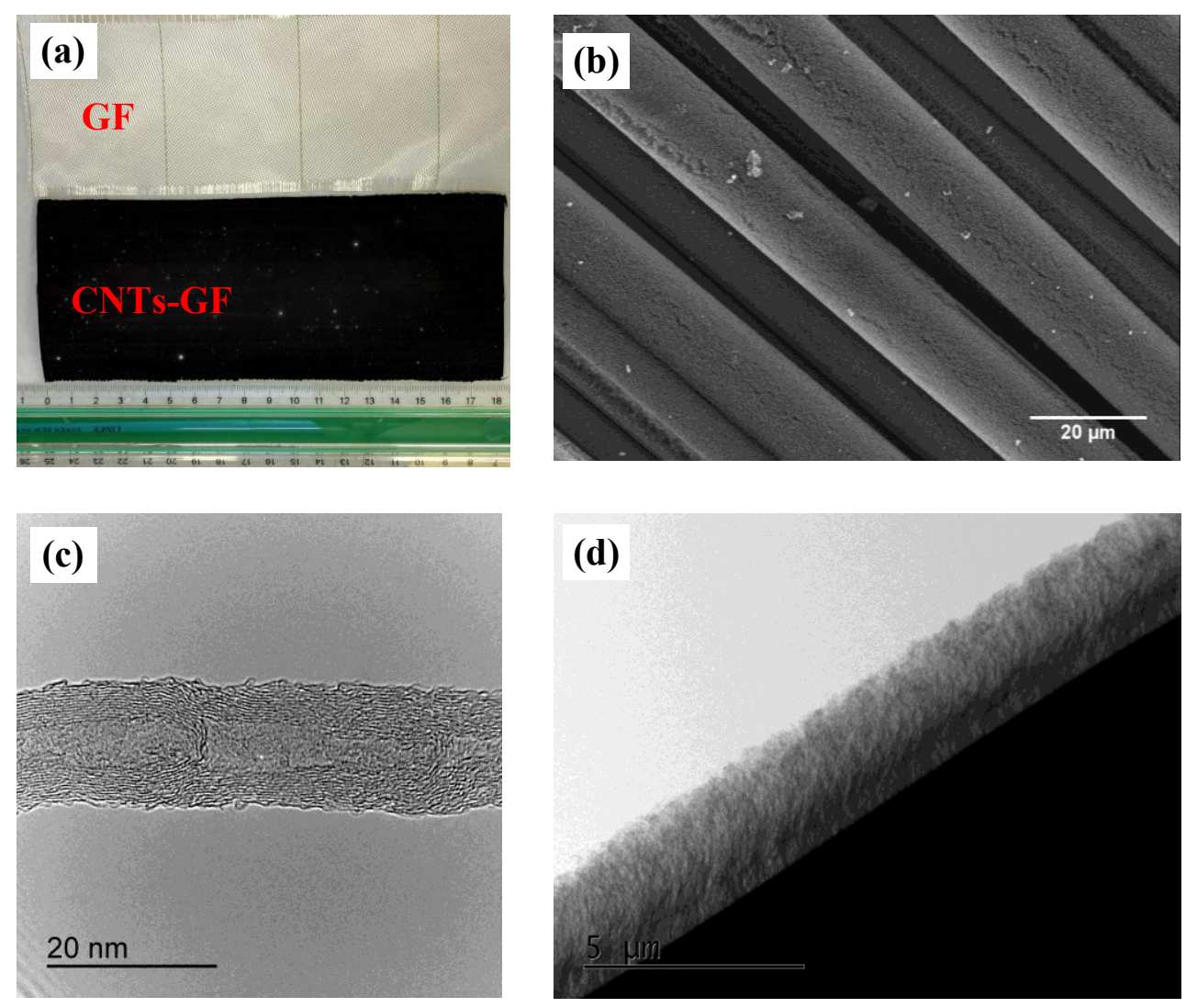

Figure 1. (a) Digital images of as-received GF tissue and the one after growth of 2 wt. \% CNTs; (b) SEM images of CNTs-GFs, and (c) high and (d) low resolution TEM images of one CNT and one CNTs-GF hybrid, respectively.

The weight ratio of CNTs grown on GFs is one of the important factors which determine the mechanical reinforcing effect of CNTs-GF and also the electrical 
properties of the final composites. In this study, the mass fraction of CNTs grown on the GF tissue can be modulated according to the requirements by adjusting the CVD synthesis conditions such as temperature and nanotube growth time. The TGA curves shown in Fig. 2 a demonstrate that the $w t_{\mathrm{CNT}}$ varies from $0 \%$, to $0.2 \%, 0.5 \%, 1 \%$, $1.5 \%, 2 \%, 3 \%$ and $7 \%$, when the CNT growth time changes from 0 to $10 \mathrm{~min}$. Of course, other $w t_{\mathrm{CNT}}$ can also be obtained by modifying the CVD conditions. Also, it can be seen that the CNTs begun to largely decompose at around $430{ }^{\circ} \mathrm{C}$ under an atmosphere consisting of as high as $50 \%$ oxygen. This temperature is much higher than the working temperatures of GFRPs. Thus, the CNTs-GF can make sure a stable reinforcing role even at elevated temperatures.

Figure $2 b$ shows a Raman spectrum of CNTs-GF in the range of $1000-1800 \mathrm{~cm}^{-1}$. The $\mathrm{G}$ band centered at $1600 \mathrm{~cm}^{-1}$ corresponds to $\mathrm{sp}^{2}$ graphite-like structure of CNT. A broad D band centered at $1324 \mathrm{~cm}^{-1}$, along with an intensity ratio $I_{D} / I_{G}$ around 1 , indicates certain amount of disorder structures in carbon nanotubes, as also shown in Fig. 1c. This is mainly due to the low synthesis temperatures used, in order to avoid the fiber property degradation generated at higher ones. It is worth noting that higher CNT fractions up to 30 wt. \% have also been obtained during our research. The increase of CNT weight ratio may change their organization state from homogenous distribution to agglomeration such as bundles and plats. These latters could cause quality defects in final composite products. Thus, the GF tissues containing much longer CNTs are not presented in this study. 
(a)

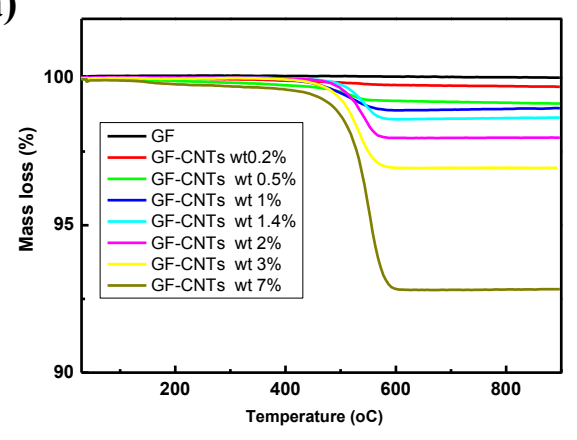

(b)

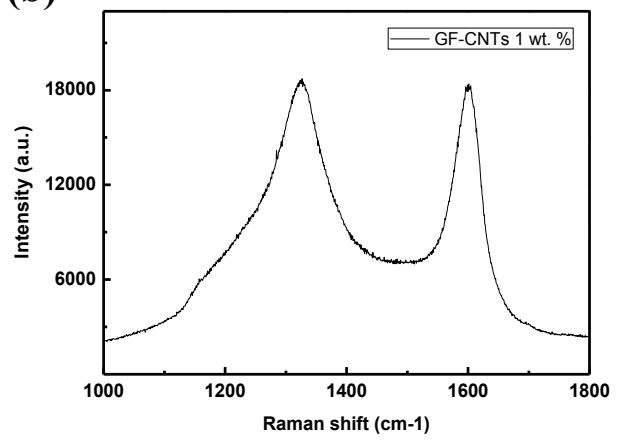

Figure 2. (a) TGA curves of CNTs-GF with varied mass fractions of CNTs, and (b) Raman spectrum of the CNTs.

The morphologies of as-received GFs and the CNTs-GF containing varied CNT mass fractions are shown in Fig. 3. The pristine GF has smooth and cylindrical surface, and its diameter is around $9 \mu \mathrm{m}$ (Fig. 2a). The fibers color turned from white to grey after growing 0.2 wt. \% nanotubes, which are very short and few. The CNTs are sparsely distributed on GF surface, as shown in Fig. 3b. The nanotube length is between several $\mathrm{nm}$ to $500 \mathrm{~nm}$, corresponding to the beginning state of CNT growth. With increasing the growth time, the CNTs become longer and denser. It can be found that the GF surface is completed covered by nanotubes when $w t_{\mathrm{CNT}}$ is beyond $0.5 \%$. As shown in Fig. 3, the apparent diameter of hierarchical CNTs-GF varies from $9 \mu \mathrm{m}$ to around 9.6, 9.8, 11.8, 14, 15.8 and $19.6 \mu \mathrm{m}$, corresponding to the CNT shell thickness of around $0.3,0.4,1.4,2.5,3.4$ and $5.3 \mu \mathrm{m}$, respectively, when CNT mass fraction ratio increases from 0 to $0.5 \%, 1 \%, 1.5 \%, 2 \%, 3 \%$ and $7 \%$, respectively. Furthermore, it can be found that the growth of CNTs was homogeneous around the 
whole fiber surface and along the whole fiber length. The CNT array forms a one-dimensional "core-shell" structure at high $w t_{\mathrm{CNT}}$.
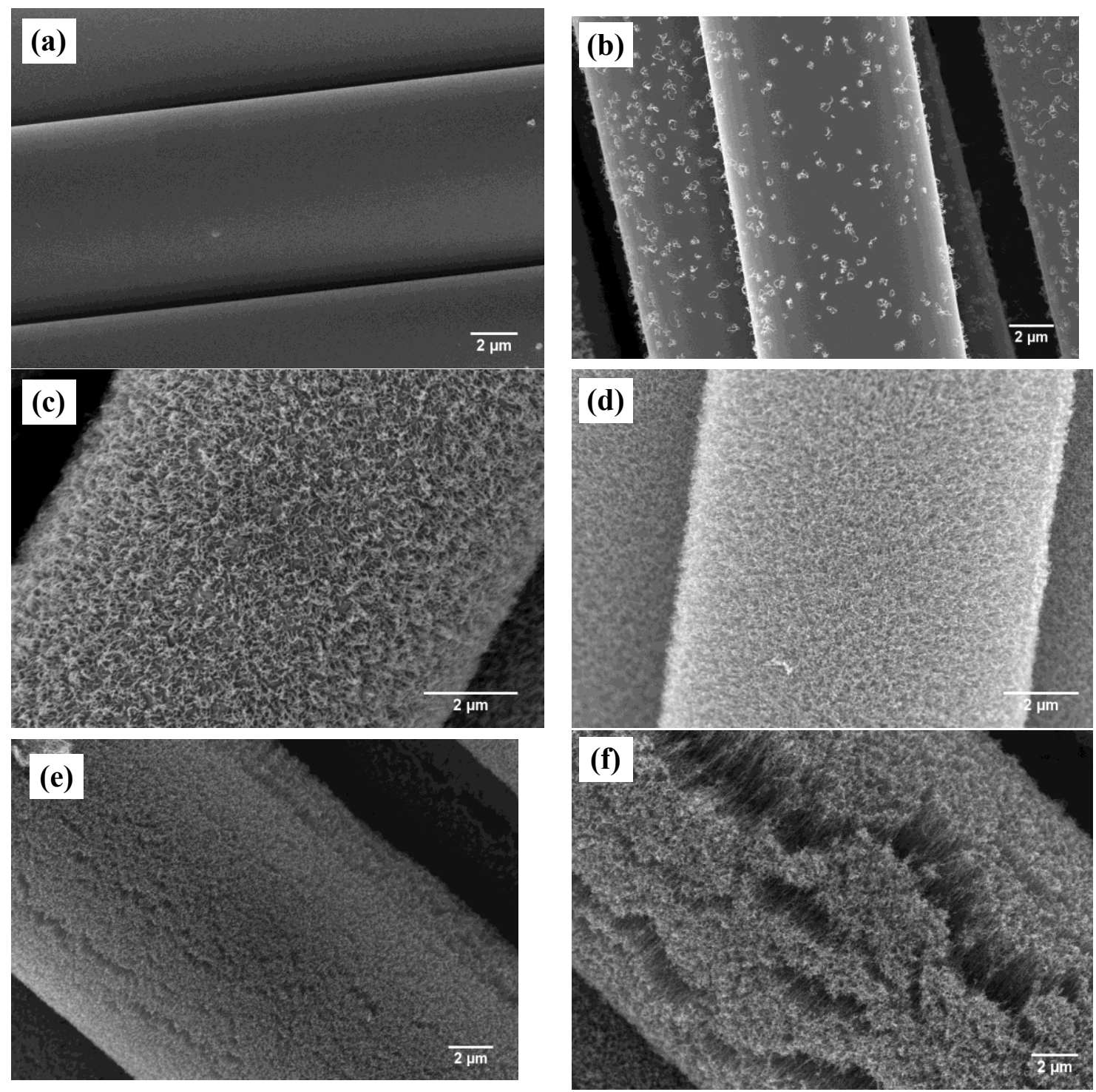

Figure 3. SEM images of as-received GF (a) and the CNTs-GF with CNTs of varied mass fractions: (b) 0.2 wt. $\%$, (c) 0.5 wt. $\%$, (d) 1 wt. $\%$, (e) 3 wt. $\%$ and (f) 7 wt. $\%$.

\subsection{Structural composites with high electrical conductivity}

The electrical conductivity of the CNTs-GF/Epoxy composites is demonstrated in Fig. 4. It can be seen that both the in-plane and through-plane electrical conductivities increase with the increase of $w t_{\mathrm{CNT}}$. The through-plane electrical conductivity is 
improved from $5 \mathrm{E}-09 \mathrm{~S} / \mathrm{m}$ to $3.5 \mathrm{~S} / \mathrm{m}$ when $w t_{\mathrm{CNT}}$ varies from 0 to $7 \%$. Meanwhile, the in-plane one is also increased from $5 \mathrm{E}-07 \mathrm{~S} / \mathrm{m}$ to $100 \mathrm{~S} / \mathrm{m}$ when $w t_{\mathrm{CNT}}$ increases from 0 to $7 \%$. Also, the increase of the in-plane and through-plane electrical conductivity follows a similar variation rule. As shown in Fig. 4b, a sharp improvement of the conductivities is observed when $w t_{\mathrm{CNT}}$ is more than $0.5 \%$. Moreover, the dielectric property measurements showed that the composites behaved as dielectric materials at $w t_{\mathrm{CNT}}=0.2 \%$, but a significant increase on both the dielectric constant and loss tangent was observed at $w t_{\mathrm{CNT}}=0.5 \%$. This indicates that continuously conductive pathways are formed in both through-thickness and in-plane directions. Therefore, the growth of CNTs on GF tissue allows modulating the composite electrical conductivity at a very wide range from nearly isolating to highly conductive ones. This is greatly desired to design composite properties such as dielectric constant or conductivity according to real service requirements.

(a)

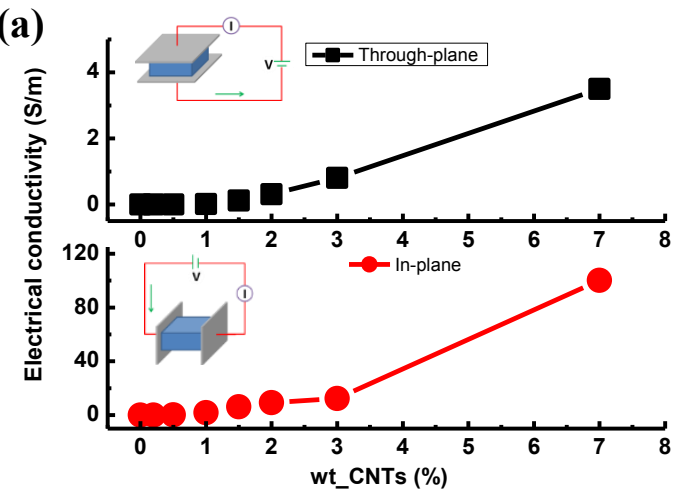

(b)

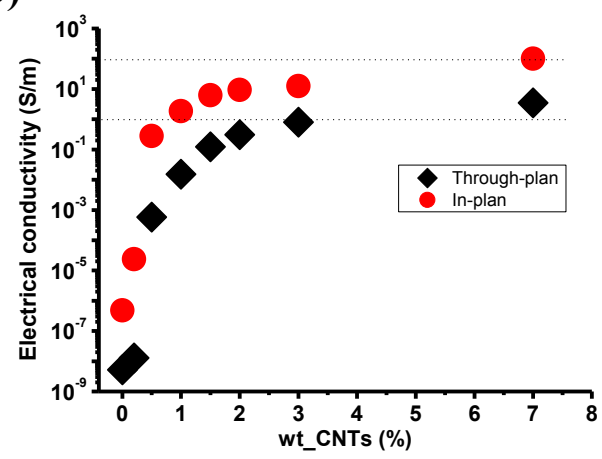

Figure 4. In-plane and through-plane electrical conductivities of the composites as a function of the mass fraction of CNTs grown on the GF: conductivity axis in linear scale (a) and in log scale (b). 
The microstructures of the GF/Epoxy and CNTs-GF/Epoxy composites were characterized by scanning electron microscopy in order to understand their electrical conduction behaviors and related mechanisms. Figure 5 shows the SEM images of the cross-sections of the composites with varied $w t_{\mathrm{CNT}}$. It is worth mentioning that the cross-section was obtained by fracturing the specimen in liquid nitrogen. The gaps between GF (with or without CNTs) and epoxy might be partially produced by the mismatch of thermal expansion coefficients of GF and epoxy, when the sample temperature abruptly changed from liquid nitrogen one to room temperature. The SEM images of the composites before being fractured (Figure S1, See supporting information) show that the original interfacial bonding between GF and epoxy is good, with no gap observed at interfacial zones.

First, few visible defects such as pores and CNT aggregates are presented in the structures, indicating that the composites have good quality. This means that the growth of CNTs on GF tissue can adapt well with currently widely used composite production techniques. In contrast, commonly used dispersion way may cause significant increase of matrix resin viscosity. ${ }^{38}$ Thus, in-situ growth of CNTs on the GF tissues can be a highly efficient way to introduce even high mass fractions of CNTs into structural composites. This advantage is highly desired to industrial sectors for their large-scale application potential.

Second, a distinguished annular region is obviously observed around each GF by SEM, when $w t_{\mathrm{CNT}}$ is higher than $0.5 \%$. This region bridges together GF and matrix bulk, forming a distinguished interphase which has the properties different from those 
of the bulk matrix. It is well known that interfacial and interphase properties take a determining role in realizing high performance fiber reinforced polymer composites. ${ }^{39}$ The introduction of CNTs could reinforce the interphase region. ${ }^{40}$ In our case, CNT volume concentration in annular interphase zones is higher than that in other parts of bulk matrix, and the CNT alignment on GF was also preserved in the composites. Similarly, the interphase region thickness increases progressively with the mass fraction and shell thickness of CNTs grown on GFs. As a result, at higher $w t_{\mathrm{CNT}}$ the interconnection between adjacent interphase regions generates increased numbers of electrical conduction pathway, thus greatly improves the electrical conductivity.

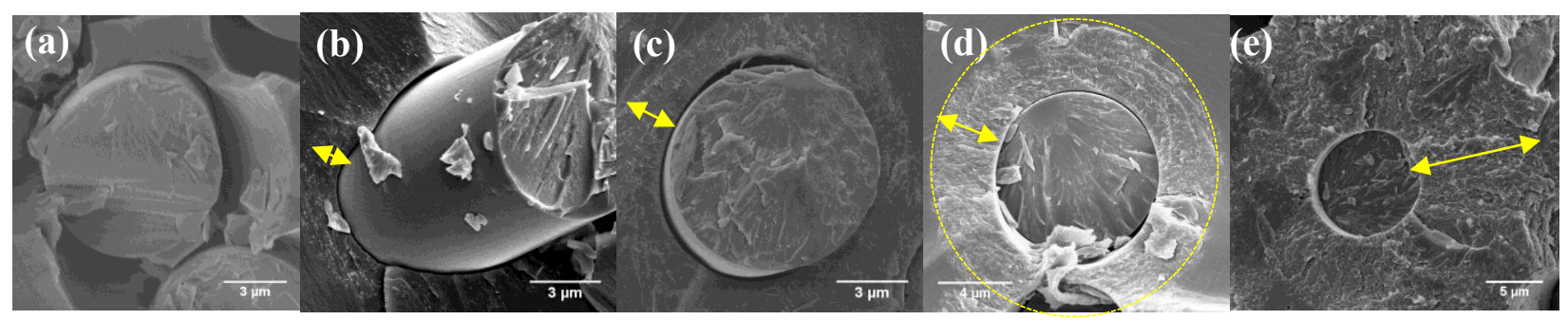

Figure 5. SEM images of interface/interphase in GF/Epoxy composite (a), and the annular ones (indicated by arrows) consisting of aligned nanotubes around glass fiber in the CNTs-GF/Epoxy composites with $w t_{\mathrm{CNT}}=0.5 \%$ (b), $w t_{\mathrm{CNT}}=1.5 \%$ (c), $w t_{\mathrm{CNT}}=3 \%$ (d) and $w t_{\mathrm{CNT}}=7 \%$ (e).

It is well known that CNTs possess much higher electrical conductivity along the axial direction than the one along radical direction. This is mainly due to their specific one-dimensional characteristic. It has been mentioned earlier that CNTs are perpendicularly aligned on the GF surface, and this organization states are still preserved in the cured composites. However, we noticed that the in-plane electrical 
conductivity of the composites is always higher than the corresponding through-plane one at each $w t_{\mathrm{CNT}}$, even dozens of times high. This is mainly attributed to the fact of the existence of resin rich interlaminar layers (RIL) between two neighboring GF layers. The RIL has been clearly observed by SEM (Fig. 6a). At certain interply zones, two CNTs-GF tissue layers are isolated from each other by epoxy which is not filled by CNTs. Consequently, the electron conduction pathways are decreased, resulting in an increase of the electrical resistance in through-plane direction. More importantly, the electrical resistivity of RIL is much higher than that of lamina, due to the isolation characteristic of epoxy. The RIL conductivity as a function of $w t_{\mathrm{CNT}}$ were evaluated according to a series model ${ }^{41}$ of six CNTs-GF laminas and five interlayers, as shown in Fig. 6b. In the model, we supposed that the RIL thickness was $10 \mu \mathrm{m}$. According to the parallel model, we assumed that the in-plane conductivity of each lamina was equal to the through-plane one. Finally, it can be found that the RIL conductivity was about $2.5 \mathrm{E}-10 \mathrm{~S} / \mathrm{m}$, equally to the pure matrix conductivity when $w t_{\mathrm{CNT}}=0$. Then, it significantly increases with $w t_{\mathrm{CNT}}$ increasing, up to $\sim 0.02 \mathrm{~S} / \mathrm{m}$ when $w t_{\mathrm{CNT}}=7 \%$. This analysis demonstrates that the interlayer resistance plays a very important role in improving the through-plane conductivity of the CNTs-GF/polymer composites. 
(a)

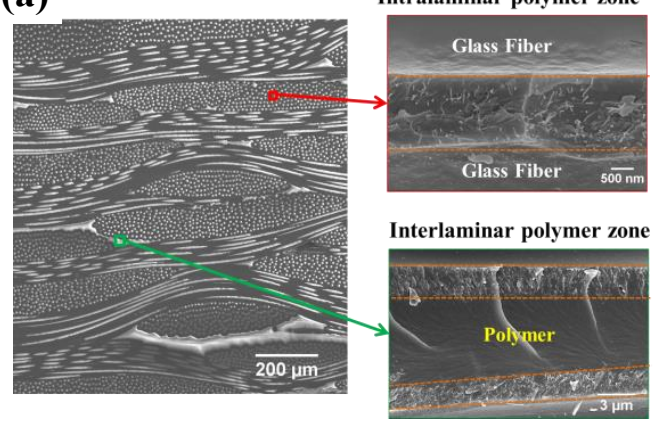

(b)

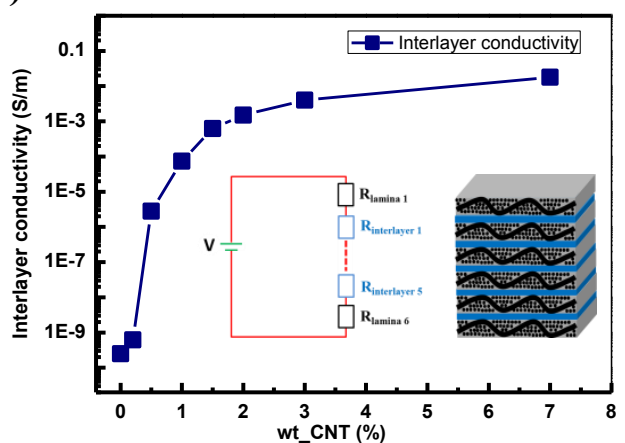

Figure 6. (a) Microscopic structure of the cross-section of CNTs-GF/Epoxy composites: polymer region between two GF fibers in a lamina and that in an interlaminar zone; (b) Evaluation of the interlayer conductivity as a function of the weight fraction of CNTs grafted on GF surface.

\subsection{Thermo-mechanical behaviors and flexural properties of the CNTs-GF/Epoxy} composites

The thermo-mechanical and flexural properties were investigated by dynamic mechanical analysis and 3-point bending test, respectively, in order to evaluate the influence of CNT growth on the structural properties of the composites. The results are summarized in Table 1. 
Table 1. Summarized results of the thermo-mechanical and flexural properties of the GF/epoxy and CNTs-GF/epoxy composites containing varied $w t_{\mathrm{CNT}}$

\begin{tabular}{|c|c|c|c|c|c|c|c|c|}
\hline \multicolumn{2}{|c|}{ Sample } & $\begin{array}{c}w t_{\mathrm{CNT}}= \\
0\end{array}$ & $\begin{array}{c}w t_{\mathrm{CNT}}= \\
0.2 \%\end{array}$ & $\begin{array}{c}w t_{\mathrm{CNT}}= \\
1 \%\end{array}$ & $\begin{array}{c}w t_{\mathrm{CNT}}= \\
1.5 \%\end{array}$ & $\begin{array}{c}w t_{\mathrm{CNT}}= \\
2 \%\end{array}$ & $\begin{array}{c}w t_{\mathrm{CNT}}= \\
3 \%\end{array}$ & $\begin{array}{c}w t_{\mathrm{CNT}}= \\
\quad 7 \%\end{array}$ \\
\hline \multicolumn{2}{|c|}{$\begin{array}{l}\text { CNT layer thickness } \\
\qquad(\mu \mathrm{m})\end{array}$} & - & 0 & 0.4 & 1.4 & 2.5 & 3.4 & 5.3 \\
\hline \multicolumn{2}{|c|}{$\begin{array}{l}\text { Laminate thickness } \\
\qquad(\mathrm{mm})\end{array}$} & 0.85 & 0.85 & 0.9 & 0.96 & 0.95 & 1 & 1.25 \\
\hline \multicolumn{2}{|c|}{$\begin{array}{l}\text { GF volume faction in } \\
\text { laminates }(\%)\end{array}$} & 59.5 & 53.5 & 51.9 & 50.6 & 46.1 & 43.9 & 34.9 \\
\hline \multicolumn{2}{|c|}{$\operatorname{Tg}\left({ }^{\circ} \mathrm{C}\right)$} & 103.2 & 103.6 & 103.5 & 104.2 & 105.2 & 104.8 & 104.9 \\
\hline \multirow{2}{*}{$\begin{array}{l}\text { Storage } \\
\text { modulus } \\
\text { at } 50^{\circ} \mathrm{C} \\
(\mathrm{GPa})\end{array}$} & Measured & 25.3 & 25.5 & 24.9 & 22.4 & 22 & 19.3 & 14.9 \\
\hline & Normalized* & 25.3 & 28.4 & 28.6 & 26.4 & 28.4 & 26.2 & 25.4 \\
\hline \multirow{2}{*}{$\begin{array}{l}\text { Flexural } \\
\text { modulus } \\
(\mathrm{GPa})\end{array}$} & Measured & 29.1 & 29.6 & 30.7 & 28.6 & 26.2 & 21.9 & 18.5 \\
\hline & Normalized ${ }^{*}$ & 29.1 & 32.9 & 35.2 & 33.6 & 33.8 & 29.7 & 31.5 \\
\hline \multirow{2}{*}{$\begin{array}{c}\text { Flexural } \\
\text { strength } \\
(\mathrm{MPa})\end{array}$} & Measured & 658 & 654 & 702 & 707 & 627 & 587 & 462 \\
\hline & Normalized* & 658 & 727.3 & 804.8 & 831.4 & 809.3 & 795.6 & 787.7 \\
\hline
\end{tabular}

${ }^{*}$ Normalized according to the glass fiber volume fraction $(59.5 \%)$ of the reference GF/Epoxy laminates.

First, the growth of CNTs on glass fibers generates an influence on the storage modulus $\left(E^{\prime}\right)$ of the composites, which represents the stiffness of a viscoelastic material. Figure 7 a shows the variation of $E^{\prime}$ as a function of $w t_{\mathrm{CNT}}$. The composite storage modulus $E^{\prime}$ at $50^{\circ} \mathrm{C}$ has nearly the same level to the GF/epoxy one, around 25 GPa when $w t_{\mathrm{CNT}}$ is no more than $1 \%$. It decreases about $13 \%$ to $22 \mathrm{GPa}$ when $w t_{\mathrm{CNT}}$ is 1.5 and $2 \%$. The further increase of $w t_{\mathrm{CNT}}$ to $3 \%$ and $7 \%$ results in a decrease of $E^{\prime}$ about $30 \%$ and $40 \%$, respectively. 
Second, Figure $7 \mathrm{~b}$ shows the loss tangent curves of the composites as a function of temperature. The glass transition temperature $\mathrm{Tg}$ value was evaluated according to the temperature value which corresponds to the loss tangent peak in a DMA curve. ${ }^{42}$ It is well known that $\mathrm{Tg}$ defines the working temperature window of a composite. It reflects the transition of the composite materials from hard glass state to soft rubber state, due to the internal movement of the polymer chains. And Tg also infers the interaction between fillers and polymer matrix in the interphase region. ${ }^{42}$ As shown in Table 1, the Tg of the CNTs-GF/Epoxy located in a narrow range between $103{ }^{\circ} \mathrm{C}$ and $105{ }^{\circ} \mathrm{C}$, comparable with the one of the reference composite (GF/Epoxy). This indicates that the growth of CNTs of $w t_{\mathrm{CNT}}$ studied in this work did not degrade thermal stability of the structural composites.
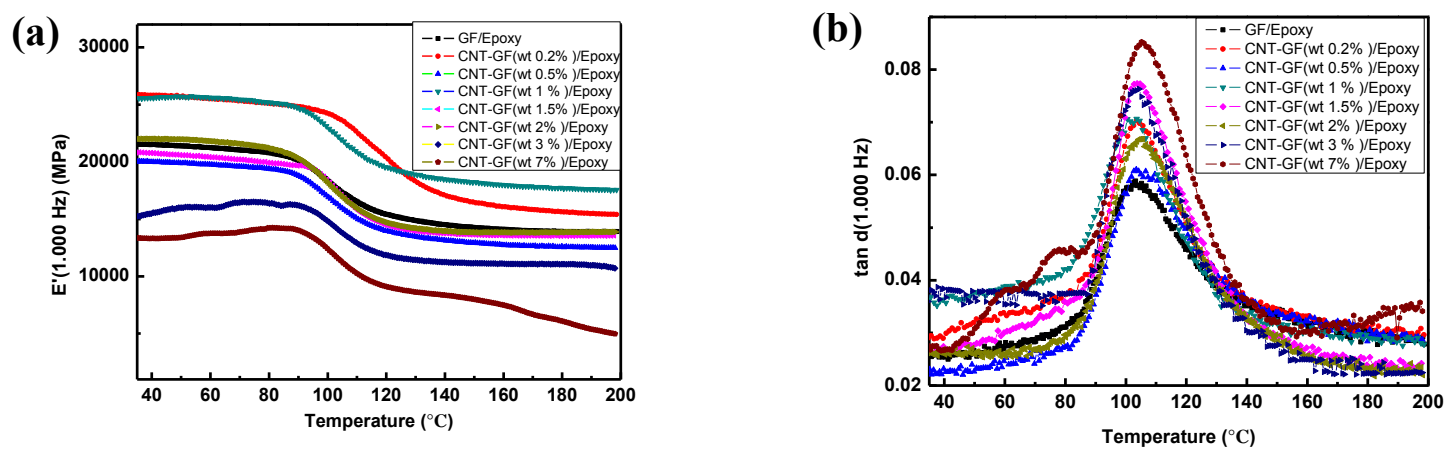

Figure 7. DMA curves of the GF/Epoxy and CNTs-GF/Epoxy composites: (a) Dynamic mechanical Modulus E’ vs. temperature, and (b) loss tangent ( $\tan \delta$ ) vs. temperature.

Third, the grafting of CNTs on GF has also shown an influence on the flexural modulus and strength of the composites. Globally speaking, the flexural modulus of the CNTs-GF/Epoxy composites keeps almost constant when $w t_{\mathrm{CNT}}$ is no more than 
$1.5 \%$. The $E^{\prime}$ of the GF-CNTs/Epoxy at $w t_{\mathrm{CNT}}=1.5 \%$ is comparable to the one $(\sim 29$ $\mathrm{GPa})$ of the GF/Epoxy reference. It begins to decrease gradually from $\sim 26.2 \mathrm{GPa}$ to $18.5 \mathrm{GPa}$ when $w t_{\mathrm{CNT}}$ varies from $2 \%$ to $7 \%$, respectively, corresponding to a decrease of $10 \%$ to $36 \%$, respectively. Meanwhile, the flexural strength of the composites increases from $658 \mathrm{MPa}$ (the reference composite) to $707 \mathrm{MPa}$ when $w t_{\mathrm{CNT}}$ increases from 0 to $1.5 \%$, corresponding to an improvement of about $7 \%$. But a further increase of $w t_{\mathrm{CNT}}$ generates a large decrease of the flexural strength, attaining up to $40 \%$ at $w t_{\mathrm{CNT}}=7 \%$.

In order to more realistically represent the effect of CNT grafting on the composite flexural properties, we must take into account the variation of the laminate thickness and the GF volume fraction in each composite. As indicated in Table 1, the increase of CNT mass fraction generates the thickening of the CNT shell on each GF and thus the composite laminate, under the experimental conditions used. The increased shell enlarges the span distance between the two adjacent GFs, and absorbs more resin during the curing process. The above mentioned thickening is particularly evident when $w t_{\mathrm{CNT}}$ is equal to $3 \%$ and $7 \%$, corresponding to an increase of $18 \%$ and $47 \%$, respectively. A further measurement of GF volume fraction in composites was conducted by burning each CNT-GF/epoxy composite at $600{ }^{\circ} \mathrm{C}$ in air atmosphere for 1 hour. The results show that the GF volume fraction indeed decreases with the increase of $w t_{\mathrm{CNT}}$. It varies gradually from $59.5 \%$ in reference composites to $\sim 35 \%$ in the CNT-GF/epoxy composites containing 7 wt. \% CNTs on GF tissue. The change of GF volume fraction undoubtedly results in the variation of the mechanical 
properties of the composites, especially in a composite reinforced by continuous fiber. Therefore, a normalization treatment of the measured composite property values was done according to the GF volume fraction in the reference composite laminates. The normalized values of the storage modulus and the flexural modulus and strength at each CNT fraction composite are correspondingly summarized in table 1 . Their improvement values compared to the reference are also demonstrated in Fig. 8. It can be seen that the grafting of homogeneous CNT shell on GF in fact improves the composite thermo-mechanical and flexural properties. When $w t_{\mathrm{CNT}}$ is no more than $2 \%$, the overall performance of the composites is progressively improved, and the optimal reinforcing performance could be obtained between $w t_{\mathrm{CNT}}=1 \%$ and $2 \%$ included. The reinforcing effect gradually diminishes when more CNT is grafted on GF surface. This might be attributed to insufficient resin infusion or immersion in the shell layer containing high areal number density CNTs, which in turn might generate less compact regions around GF. Moreover, this might also impact inversely interfacial adhesion between epoxy and GF. As a result, the load transfer reinforcing efficiency between GF and matrix was diminished. But the CNTs-GF/Epoxy composite flexural properties are still higher than the reference one containing the same fiber volume fraction, even at $w t_{\mathrm{CNT}}=7 \%$. In this case, an amelioration of composite preparation parameters such as hot pressure or vacuum degree could enhance resin immersion and decrease laminate thickness. It is highly desired to keep their excellent mechanical properties when the structural composites are added with additional functional properties, such improving electrical conductivity by adding 
conductive nanomaterials.

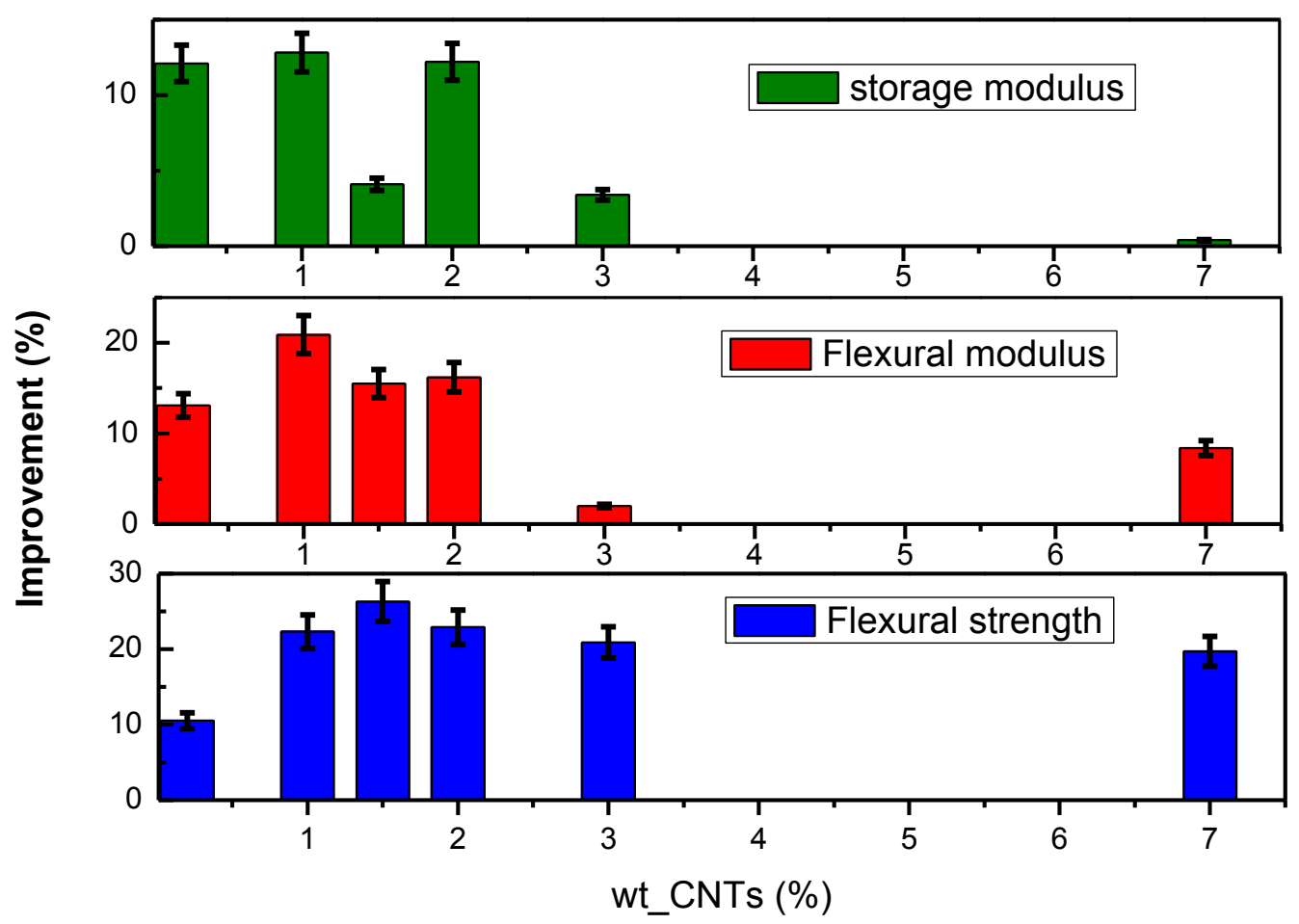

Figure 8. Improvement of the storage modulus and the flexural modulus and strength of the CNTs- GF/Epoxy with varied $w t_{\mathrm{CNT}}$, compared to the reference GF/Epoxy obtained under the same experimental condition.

\subsection{Interfacial adhesion properties}

The evaluation of interfacial adhesion property is important to better understand the previously mentioned mechanical reinforcing effects in the CNTs-GF composites. As we know, there are multiple interfaces included in the hierarchical CNTs-GF composites: $\mathrm{CNTs} / \mathrm{GF}, \mathrm{CNTs} /$ matrix and GF/matrix one. Thus, the interfacial shear strength (IFSS) of CNTs-GF in the composites is a general result of the interaction of these three interfaces. 
In the first place, the single tensile test was conducted in order to study the influence of CVD procedure and CNT grafting on the mechanical properties of glass fiber. The average fiber elongation and tensile strength at break along with Young's Modulus results are summarized in the table 2. It can be found that both the strength and elongation at break of the CNTs-GF are higher than those of as-received GF, respectively. The Young's modulus of the CNTs-GF is comparable or higher than that of the GF. Commonly, certain damage to the GF and CNT-GF might be caused during separating operation of a single filament from a fiber bundle which is woven in the tissue. The damages may result in a reduced fiber modulus value. And this deterioration might be much significant in case of as-received GF due to sticking effect of surface sizing. Thus, we further did the mechanical tensile tests using single GF and CNTs-GF bundle. The representative force-displacement curves (Figure S2, See supporting information) confirm that the modulus of GF bundle is well retained after the growth of CNTs. Both the fiber bundle elongation and tensile strength at break are improved when $w t_{\mathrm{CNT}}$ varies from $0.2 \%$ to $2 \%$. However, these improvements disappear when a higher content of CNTs is grafted on GF, such as CNTs-GF with 3 and 7 wt. \% nanotubes. The latter is different to the results obtained from the single fiber test, which might be due to the enlarged glass fiber misalignment in a bundle generated by grafting long CNT shell.

The above results demonstrate that no mechanical property degradation of glass fiber has been generated in the CVD procedure used for CNT growth. Moreover, the 
GF mechanical properties could be further improved when the optimized CVD conditions and CNT arrangement are used.

Table 2. Elongation and tensile strength at break and Young's modulus of single GF and single CNTs-GF with varied $w t_{\mathrm{CNT}}$

\begin{tabular}{|c|c|c|c|c|c|c|c|}
\hline & \multirow[b]{2}{*}{ GF } & \multicolumn{6}{|c|}{ CNTs-GF } \\
\hline & & $\begin{array}{l}w t_{\mathrm{CNT}} \\
0.2 \%\end{array}$ & $\begin{array}{c}w t_{\mathrm{CNT}} \\
1 \%\end{array}$ & $\begin{array}{l}w t_{\mathrm{CNT}} \\
1.5 \%\end{array}$ & $\begin{array}{c}w t_{\mathrm{CNT}} \\
2 \%\end{array}$ & $\begin{array}{c}w t_{\mathrm{CNT}} \\
3 \%\end{array}$ & $\begin{array}{c}w t_{\mathrm{CNT}} \\
7 \%\end{array}$ \\
\hline $\begin{array}{l}\text { Elongation at } \\
\text { break }(\%)\end{array}$ & 1.7 & 2.0 & 2.3 & 2.0 & 2.2 & 1.8 & 1.9 \\
\hline $\begin{array}{l}\text { Strength at break } \\
(\mathrm{MPa})\end{array}$ & 1085 & 1451 & 1297 & 1473 & 1285 & 1127 & 1538 \\
\hline $\begin{array}{c}\text { Young's } \\
\text { Modulus (GPa) }\end{array}$ & 64 & 76.8 & 57.9 & 74.6 & 59.7 & 68.2 & 75.2 \\
\hline
\end{tabular}

Furthermore, the influence of CNTs on interfacial shear strength between fiber and epoxy was investigated via single fiber fragmentation tests. ${ }^{43}$ The IFSS can be estimated from the Kelly-Tyson model: ${ }^{44}$

$$
\operatorname{IFSS}=\sigma_{\mathrm{fb}}\left(L_{\mathrm{c}}\right) d_{f} /\left(2 L_{\mathrm{c}}\right)
$$

where $d_{f}$ is the fiber diameter, $\sigma_{f b}\left(L_{\mathrm{c}}\right)$ is the fiber strength at the saturation length $L_{\mathrm{c}}=$ $4 L_{\mathrm{s}} / 3$ ( $L_{\mathrm{s}}$ is the average fiber length at saturation).

The $\sigma_{f b}\left(L_{c}\right)$ value can be estimated by using a Weibull distribution for the fiber strength,

$$
\sigma_{f b}\left(L_{\mathrm{c}}\right)=\sigma_{0}\left(L_{c} / L_{0}\right)^{-1 / m} \Gamma(1+1 / m)
$$

where $\Gamma$ is the Gamma function, $\sigma_{0}$ and $m$ are the scale and shape parameters of the Weibull strength distribution at the reference length $L_{0}$, respectively. These 
parameters were estimated from strength data determined at one single gauge length by fitting the distribution of failure probability. ${ }^{43,45}$

The obtained results are summarized in table 3 . It can be seen that the average critical fragment length of GF is shorter than that of CNTs-GF, indicating a better interfacial bonding strength with GF. Indeed, only the matrix breaks were observed in the specimen after the fragmentation test. The estimated IFSS of GF is about $31 \mathrm{MPa}$. It was mentioned previously that as-received GF contains a surface sizing which protects glass fiber from manipulation deterioration and improves their interfacial bonding with polymer matrix in the composites. The growth of CNTs was conducted at the temperature above $550{ }^{\circ} \mathrm{C}$, and the sizing on the surface was removed due to heat decomposition. It can be found that the fiber fragment length increases after CNT growth, compared to that of GF. The CNTs-GF hybrids with CNT fractions other than 1.5 wt. \% have demonstrated lower IFSS, compared to the as-received GF. The CNTs-GF with 7 wt. \% CNTs shows the lowest IFSS. This is also confirmed by only debonding failure mode observed in the sample after fragmentation. Thus, the growth of too high fraction of CNTs decreases interfacial connection efficiency between GF and epoxy. The IFSS of the CNTs-GF with 1.5 wt. \% nanotubes is about $7 \%$ higher than the one of the as-received GF. This might be attributed to the relatively high strength at break and appropriate CNT array length of this kind of CNTs-GF, as well as sufficient glass fiber surface available for epoxy bonding.

In comparison with the results obtained by Tamrakar et al. $^{34}$ using an electrophoretic deposition method, the IFSS improvement obtained in this work is 
relatively lower, even though different kinds of GF and polymer are used. This difference might be due to the CNT surface properties, because the functionalized CNTs are used in the former work, instead of as-grown pristine CNTs in this work.

Table 3. Evaluation of the interfacial shear strength of the GF and CNTs-GF in the composites

\begin{tabular}{|c|c|c|c|c|c|c|}
\hline & \multirow{2}{*}{ GF } & \multicolumn{5}{|c|}{ CNTs-GF } \\
\hline & & $\begin{array}{c}w t_{\mathrm{CNT}} \\
1 \% \\
\end{array}$ & $\begin{array}{l}w t_{\mathrm{CNT}} \\
1.5 \% \\
\end{array}$ & $\begin{array}{c}w t_{\mathrm{CNT}} \\
2 \% \\
\end{array}$ & $\begin{array}{c}w t_{\mathrm{CNT}} \\
3 \% \\
\end{array}$ & $\begin{array}{c}w t_{\mathrm{CNT}} \\
7 \% \\
\end{array}$ \\
\hline Number of fragments & 36 & 26 & 30 & 26 & 25 & 19 \\
\hline $\begin{array}{l}\text { Average fiber critical } \\
\text { length, } L \mathrm{c}(\mathrm{mm})\end{array}$ & 0.37 & 0.51 & 0.44 & 0.51 & 0.53 & 0.7 \\
\hline Weibull shape parameter & 4.81 & 5.53 & 4.87 & 4.5 & 3.7 & 5 \\
\hline $\begin{array}{l}\text { Weibull scale parameter } \\
\qquad(\mathrm{MPa})\end{array}$ & 1085 & 1297 & 1473 & 1285 & 1127 & 1538 \\
\hline $\begin{array}{l}\text { Interfacial shear strength } \\
\qquad(\mathrm{MPa})\end{array}$ & 31 & 22.5 & 33.4 & 25.9 & 26 & 19.7 \\
\hline
\end{tabular}

Additionally, the wetting property of the GF after grafting CNTs was verified by the contact angle test. The digital images of microdroplets and contact angle values measured with GF and CNTs-GF are summarized in Figure S3 (See supporting information). It can be seen that the contact angle of the epoxy is slightly increased from $\sim 46^{\circ}$ on as-received GF to around $50^{\circ}$ on GF after the growth of CNTs. This is mainly attributed to the inert interfacial characteristic of as-grown CNTs. This observation is consistent with the small increase of the average fiber critical fragment 
length demonstrated in table 3 . However, this small increment does not significantly influence the immersion of the epoxy on CNTs-GF during composite fabrication, considering the good composite quality obtained. This also agrees with the IFSS and $\mathrm{Tg}$ of the composites at varied $w t_{\mathrm{CNT}}$. On the other hand, the wetting property indicates that additional surface treatment of the CNTs-GF could further improve the interfacial properties of CNTs-GF hybrid in the polymer composites.

\subsection{Damage-related resistance variation of the composites during Flexural testing}

In addition, the variation of the electrical resistance of the CNTs-GF/Epoxy was in-situ monitored during the flexural deformation processes, as shown schematically in Fig. 9a. Two electrode wires were pre-fixed at the two extremities of each specimen which were coated by conductive silver paint, and then connected to a voltage/current sourcing measurement instrument during the flexural bending tests. Two examples are given in Fig. 9b and c. Firstly, for the CNTs-GF/Epoxy composites with $w t_{\mathrm{CNT}}=0.2 \%$, the $\Delta \mathrm{R} / \mathrm{R}_{0}$ shows a stepwise increasing trend with the increase in flexural strain, as shown in Fig. 9b. In this case, CNTs are very short, and sparely distributed on the surface of GF, as shown in Fig. $3 b$. The initial $\mathrm{R}_{0}$ measured is high, around 5.1E7 $\Omega$. A continuously electrically conductive network is not formed yet in the matrix in the through-plane direction, according to the conductivity measurement results shown in Fig. $\mathbf{4 b}$. Nevertheless, certain localized connections established in the interphase regions between two touched GFs, but connection points should be much small. As a result, this kind of connection networks is very sensitive to strain, 
and it could be destroyed due to deformation or microcracks especially generated at high flexural strain. This could explain the reason that there are several fluctuations at low strain of the electrical resistance of the composites.

Second, for the CNTs-GF/Epoxy composites with $w t_{\mathrm{CNT}}=1 \%$, a continuous conductive pathway is already formed inside the matrix, and thus the initial electrical resistance $\mathrm{R}_{0}$ is lower, about $2.7 \mathrm{E} 5 \Omega$, than the one at $w t_{\mathrm{CNT}}=0.2 \%$. It is found that when the stress is lower than ultimate flexural stress, the $\Delta R / R_{0}$ also exhibits a increasing behavior with increase of the deformation, as shown in Fig. 9c. After the ultimate stress point, the fracture occurs inside the composites and the stress decreases sharply. At the same time, the $\Delta \mathrm{R} / \mathrm{R}_{0}$ also decreases simultaneously, instead of continuously increasing. It might be due to certain reconstruction of conductive network at the upper surface and increased contact points at the lower surface of the specimen. The above mentioned damage-related resistance variation might be related to the CNT arrangement on GF and their mass fraction in epoxy matrix. But the detailed mechanism investigation will be conducted in latter research. The specific resistance variation behaviors during flexural deformation show the application potential of the hierarchical CNTs-GF reinforcement for in-situ structure health monitoring of the composites and devices under real service conditions. 
(a)
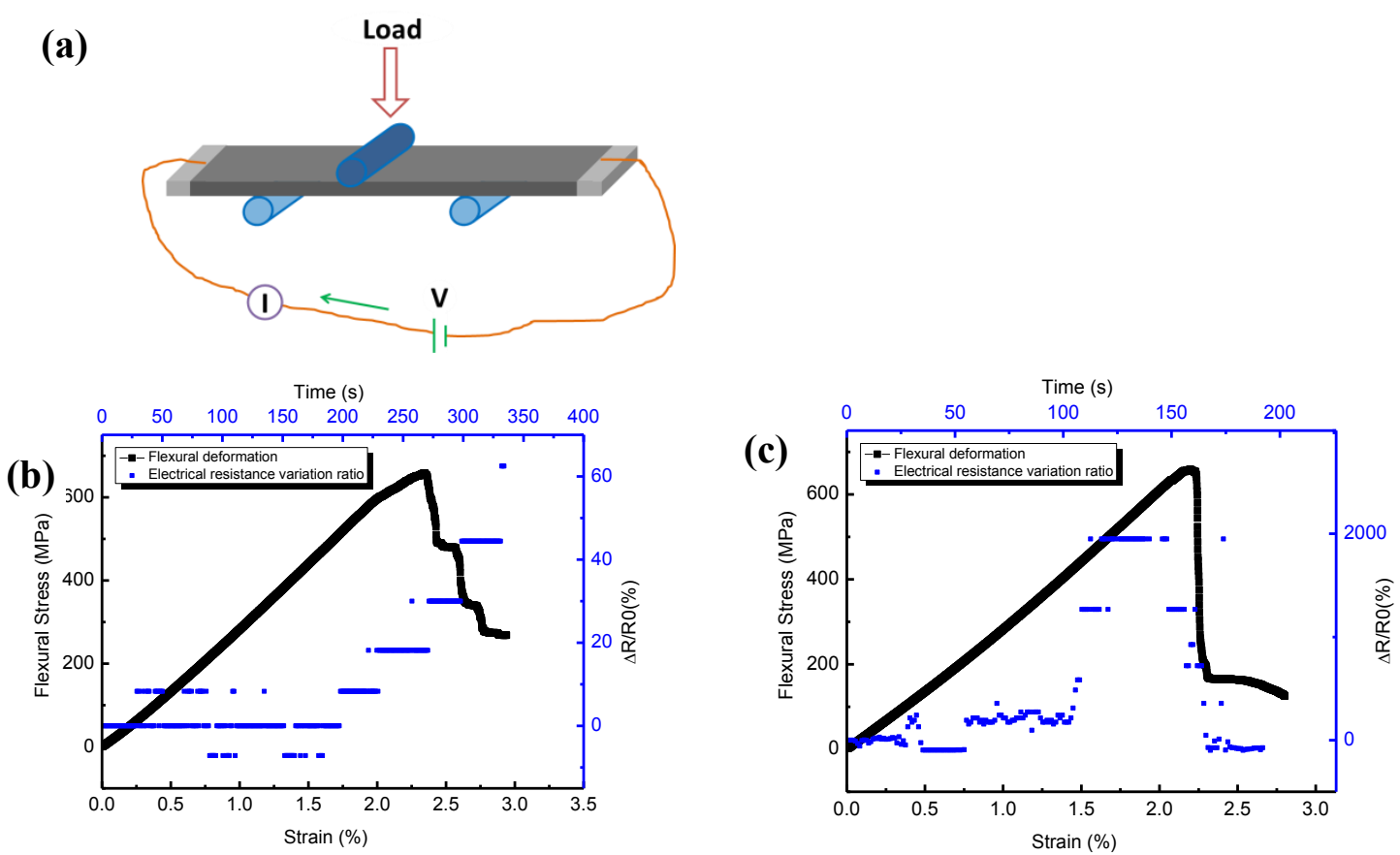

Figure 9. Resistance variations $\left(\Delta \mathrm{R} / \mathrm{R}_{0}\right)$ of the CNTs-GF/Epoxy composites under flexural deformation. (a) Schematic representing the electrode connection; (b) The CNTs-GF/Epoxy composites with $w t_{\mathrm{CNT}}=0.2 \%$ and initial resistance $\mathrm{R}_{0}=5.1 \mathrm{E} 7 \Omega$; and (c) the CNTs-GF/Epoxy composites with $w t_{\mathrm{CNT}}=1 \%$ and initial resistance $\mathrm{R}_{0}=2.7 \mathrm{E} 5 \Omega$.

\section{Conclusions}

In summary, in-situ growth of CNTs on glass fiber tissue was achieved by a one-step CVD, and the grafted CNTs homogeneously and perpendicularly aligned on the surface of each fiber, forming one dimensional "core-shell" structure. We demonstrated that the CNT mass fraction and shell thickness could be modulated in a controlled way by varying the CVD conditions. The hierarchical CNTs-GF fibers were used to produce multifunctional structural composites. The in-plane and through-plane electrical conductivities of as-produced composites greatly increased as 
a function of the weight fraction of CNTs grafted on the GF tissue, as high as $100 \mathrm{~S} / \mathrm{m}$ and $3.5 \mathrm{~S} / \mathrm{m}$ at $w t_{\mathrm{CNT}}=7 \%$, respectively. Furthermore, the detailed studies on the thermo-mechanical and flexural properties demonstrated the CNTs-GF/Epoxy composites exhibited not only high electrical conductivity but also improved structural properties of GF composites, with retention of $100 \%$ of their original thermal stability. The reinforcing effects are due to the improved CNTs-GF properties and specific CNT arrangement. Additionally, the electrical resistance variation of the CNTs-GF/Epoxy composites was found very sensitive to the composite internal fracture, which is highly desired to structural health monitoring applications. Thus, the CNTs-GF with aligned CNTs endows conventional GFRPs with excellent multifunctional properties, while improving their original structural properties. This allows extending GFRP applications in the fields of aeronautics and aerospace, automobile, industrial infrastructures, etc.

\section{ACKNOWLEDGMENT}

The authors thank Mr. Paul HAGHI-ASHTIANI for TEM characterization. X. Lu,

M. Yang, and Y. Liu gratefully acknowledge the financial support of China Scholarship Council for their PhD studies. 


\section{REFERENCES}

(1) Mallick, P.K. Fiber-Reinforced Composites: Materials, Manufacturing, and Design, $3^{\text {rd }}$ Ed; CRC Press Taylor \& Francis: New York, 2008

(2) Harris, B. Eengineering Composite Materials, The Institute of Materials: London, 1999

(3) Gao, S.; Zhuang R.; Zhang J.; Liu, J.; Mader E. Glass Fibers with Carbon Nanotube Networks as Multifunctional Sensors. Adv.Funct.Mater. 2010, 20(12), 1885- 1893.

(4) Gibson, R.F. A Review of Recent Research on Mechanics of Multifunctional Composite Materials and Structures. Compos. Struct. 2010, 92(12), 2793-2810.

(5) Ferreira, A.D.B.L.; Nóvoa, P.R.O.; Marques, A.T. Multifunctional Material Systems: A State-of-the-art Review. Compos. Struct. 2016, 151, 3-35.

(6) Markov, A.; Fiedler, B.; Schulte, K. Electrical Conductivity of Carbon Black/Fibres Filled Glass-Fibre-Reinforced Thermoplastic Composites. Composites, Part A 2006, 37(9), 1390-1395.

(7) Friedrich, K. Multifunctionality of Polymer Composites. William Andrew Publishing: Oxford, 2015, pp3-41.

(8) Wichmann, M.H.G.; Sumfleth, J.; Gojny, F.H.; Quaresimin, M.; Fiedler, B.; Schulte, K. Glass-Fibre-Reinforced Composites with Enhanced Mechanical and Electrical Properties - Benefits and Limitations of a Nanoparticle Modified Matrix. Eng. Fract. Mech. 2006, 73(16): 2346-2359.

(9) Boeger, L.; Wichmann, M.H.G.; Meyer, L.O.; Schulte, K. Load and Health 
Monitoring in Glass Fibre Reinforced Composites with an Electrically Conductive Nanocomposite Epoxy Matrix. Compos. Sci. Technol. 2008, 68, 1886-1894.

(10) Grimmer, C.S.; Dharan, C.K.H. High-cycle Fatigue of Hybrid Carbon Nanotube/Glass Fiber/Polymer Composites. J. Mater. Sci. 2008, 43, 4487-4492.

(11) Liao, L.; Wang, X.; Fang, P.; Liew, K.M.; Pan, C. Interface Enhancement of Glass Fiber Reinforced Vinyl Ester Composites with Flame-Synthesized Carbon Nanotubes and Its Enhancing Mechanism. ACS Appl. Mater. Interfaces 2011, 3, 534-538.

(12) Warrier, A.; Godara, A.; Rochez, O.; Mezzo, L.; Luizi,F.; Gorbatikh, L.; Lomov S.V.; VanVuure, A. W.; Verpoest, I. The Effect of Adding Carbon Nanotubes to Glass/Epoxy Composites in the Fibre Sizing and/or the Matrix. Composites, Part A 2010, 41, 532-538.

(13) Moniruzzaman, M.; Winey, K.I. Polymer Nanocomposites Containing Carbon Nanotubes. Macromolecules 2006, 39, 5194-5205.

(14) Li, W.; He, D.; Dang, Z.; Bai, J. In Situ Damage Sensing in the Glass Fabric Reinforced Epoxy Composites Containing CNT-A12O3 Hybrids. Compos. Sci. Technol. 2014, 99, 8-14.

(15) Li, W.; He, D.; Bai, J. The Influence of Nano/Micro Hybrid Structure on the Mmechanical and Self-sensing Properties of Carbon Nanotube-Microparticle Reinforced Epoxy Matrix Composite. Composites, Part A 2013, 54, 28-36.

(16) Thostenson, E.T.; Li, W. Z.; Wang, D. Z.; Ren, Z. F.; Chou, T. W. Carbon Nanotube/Carbon Fiber Hybrid Multiscale Composites. J. Appl. Phys. 2002, 91, 
6034-6037.

(17) Riccardis, M.F.D.; Carbone, D.; Makris, Th. D.; Giorgi, R.; Lisi, N.; Salernitano,

E. Anchorage of Carbon Nanotubes Grown on Carbon Fibres. Carbon 2006, 44, 671-674

(18) Qian, H.; Bismarck, A.; Greenhalgh, E.S.; Kalinka, G.; Shaffer, M. S. P. Hierarchical Composites Reinforced with Carbon Nanotube Grafted Fibers: The Potential Assessed at the Single Fiber Level. Chem. Mater. 2008, 20, 1862-1869.

(19) Kim, K.J.; Kim, J.; Yu, W.-R.; Youk, J. H.; Lee, J. Improved Tensile Strength of Carbon Fibers Undergoing Catalytic Growth of Carbon Nanotubes on Their Surface. Carbon 2013, 54, 258-267.

(20) Khan, S.U.; Kim, J.-K. Impact and Delamination Failure of Multiscale CNT-FRP Composites: A Review. Int. J. Aeronaut.Space 2011, 12, 115-133.

(21) Lee, S.E.; Lee, W. J.; Oh, K. S.; Kim, C. G. Broadband All Fiber-Reinforced Composite Radar Absorbing Structure Integrated by Inductive Frequency Selective Carbon Fiber Fabric and Carbon-Nanotube-Loaded Glass Fabrics. Carbon 2016, 107, $564-572$

(22) Tzounis, L.; Kirsten, M.; Simon, F.; Mäder, E.; Stamm M. The Interphase Microstructure and Electrical Properties of Glass Fibers Covalently and Non-Covalently Bonded with Multiwall Carbon Nanotubes. Carbon 2014, 73, 310-324.

(23) Tzounis, L.; Debnath, S.; Rooj, S.; Fischer, D.; Mäder, E.; Das, A.; Stamm, M.; Heinrich, G. High Performance Natural Rubber Composites with a Hierarchical 
Reinforcement Structure of Carbon Nanotube Modified Natural Fibers. Mater. Des. 2014, $58,1-11$

(24) Tzounis, L.; Liebscher, M.; Tzounis, A.; Petinakis, E.; Paipetis, A.S.; Mäder E.;

Stamm M. CNT-Grafted Glass Fibers as a Smart Tool for Epoxy Cure Monitoring, UV-Sensing and Thermal Energy Harvesting in Model Composites. RSC Adv. 2016, $6,55514-55525$

(25) Boroujeni, A.Y.; Tehrani, M.; Manteghi, M.; Zhou, Z.; Al-Haik, M. Electromagnetic Shielding Effectiveness of a Hybrid Carbon Nanotube/Glass Fiber Reinforced Polymer Composite. J. Eng. Mater. Technol. 2016, 138(4), 041001-041001.

(26) Sebastian, J.; Schehl, N.; Bouchard, M.; Boehle, M.; Li, L.; Lagounov, A.; Lafdi, K. Health Monitoring of Structural Composites with Embedded Carbon Nanotube Coated Glass Fiber Sensors. Carbon 2014, 66, 191-200.

(27) Hao, B.; Ma, Q.; Yang, S.; Mäder, E.; Ma, P. Comparative Study on Monitoring Structural Damage in Fiber-Reinforced Polymers Using Glass Fibers with Carbon Nanotubes and Graphene Coating. Compos. Sci.Technol. 2016, 129, 38-45.

(28) Zhang, J.; Zhuang, R.; Liu, J.; Mäder, E.; Heinrich, G.; Gao, S. Functional Interphases with Multi-walled Carbon Nanotubes in Glass Fibre/Epoxy Composites. Carbon 2010, 48, 2273-2281.

(29) Zhang, J.; Liu, J.; Zhuang, R.; Mäder, E.; Heinrich, G.; Gao, S. Single MWNT-Glass Fiber as Strain Sensor and Switch. Adv. Mater. 2011, 23, 3392-3397.

(30) Rahaman, A.; Kar, K.K. Carbon Nanomaterials Grown on E-glass Fibers and 
Their Application in Composite. Compos. Sci. Technol. 2014, 101, 1-10.

(31) An, Q.; Rider, A.N.; Thostenson, E.T. Hierarchical Composite Structures Prepared by Electrophoretic Deposition of Carbon Nanotubes onto Glass Fibers. ACS Appl. Mater. Interfaces 2013, 5, 2022-2032.

(32) Davis, D. C.; Wilkerson, J. W.; Zhu, J.; Ayewah, D. O. O. Improvements in Mechanical Properties of a Carbon Fiber Epoxy Composite Using Nanotube Science and Technology. Compos. Struct. 2010, 92 (11), 2653-2662.

(33) Pillin, I.; Castro, M.; Nag Chowdhury, S.; Feller, J.-F. Robustness of Carbon Nanotube-Based Sensor to Probe Composites' Interfacial Damage in Situ. J. Compos. Mater. 2016, 50,109-113

(34) Tamrakar, S.; An, Q.; Thostenson, E.T.; Rider, A. N.; (Gama) Haque, B. Z.; GillespieJr, J. W. Tailoring Interfacial Properties by Controlling Carbon Nanotube Coating Thickness on Glass Fibers Using Electrophoretic Deposition. ACS Appl. Mater. Interfaces 2016, 8 (2), 1501-1510

(35) Karakaya, M.; Zhu, J.; Raghavendra, A. J.; Podila, R.; Parler Jr., S. G.; Kaplan, J. P.; Rao A. M. Roll-to-roll production of spray coated N-doped carbon nanotube electrodes for supercapacitors. Appl. Phys. Lett. 2014, 105, 263103-4

(36) De Volder, M.; Tawfick, S. H.; Park, S.J.; Copic, D.; Zhao, Z.; Lu, W.; Hart, A. J. Diverse 3D Microarchitectures Made by Capillary Forming of Carbon Nanotubes. Adv. Mater. 2010, 22, 4384-4389.

(37) Wang, X.; Yong, Z. Z.; Li, Q. W.; Bradford, P. D.; Liu, W.; Tucker, D. S.; Cai, W.; Wang, H.; Yuan, F. G.; Zhu, Y. T. Ultrastrong, Stiff and Multifunctional Carbon 
Nanotube Composites. Mater. Res. Lett. 2013, 1, 19-25.

(38) Rahatekar, S.S.; Koziol, K. K. K.; Butler, S. A.; Elliott, J. A.; Shaffer, M. S. P.;

Mackley, M. R.; Windle, A.H. Optical Microstructure and Viscosity Enhancement for an Epoxy Resin Matrix Containing Multiwall Carbon Nanotubes. J. Rheol. 2006, 50, 599-610.

(39) Zhang, X.; Fan, X.; Yan, C.; Li, H.; Zhu, Y.; Li, X.; Yu, L. Interfacial Microstructure and Properties of Carbon Fiber Composites Modified with Graphene Oxide. ACS Appl. Mater. Interfaces 2012, 4, 1543-1552.

(40) Tehrani, M.; Safdari, M.; Boroujeni, A. Y.; Razavi, Z.; Case, S. W.; Dahmen, K.; Garmestani, H.; Al-Haik, M. S. Hybrid Carbon Fiber/Carbon Nanotube Composites for Structural Damping Applications. Nanotechnology 2013, 24, 155704.

(41) Yu, H.; Heider, D.; Advani, S. A 3D Microstructure Based Resistor Network Model for the Electrical Resistivity of Unidirectional Carbon Composites. Compos. Struct. 2015, 134, 740-749.

(42) Odegard, G.M.; Bandyopadhyay, A. Physical Aging of Epoxy Polymers and Their Composites. J. Polym. Sci., Part B: Polym. Phys. 2011, 49, 1695-1716.

(43) Etcheverry, M.; Barbosa, S. E. Glass Fiber Reinforced Polypropylene Mechanical Properties Enhancement by Adhesion Improvement. Materials 2012, 5(6), 1084-1113.

(44) Kelly, A.; Tyson, W.R. Tensile Properties of Fibre-Reinforced Metals: Copper/Tungsten and Copper/Molybdenum. J. Mech. Phys. Solids 1965, 13(6), 329-350. 
(45) Mahmood, H.; Tripathi, M.; Pugno, N.; Pegoretti, A. Enhancement of Iinterfacial Adhesion in Glass Fiber/Epoxy Composites by Electrophoretic Deposition of Graphene Oxide on Glass Fibers. Compos. Sci. Technol. 2016, 126, 149-157. 
Table of Contents Graphic

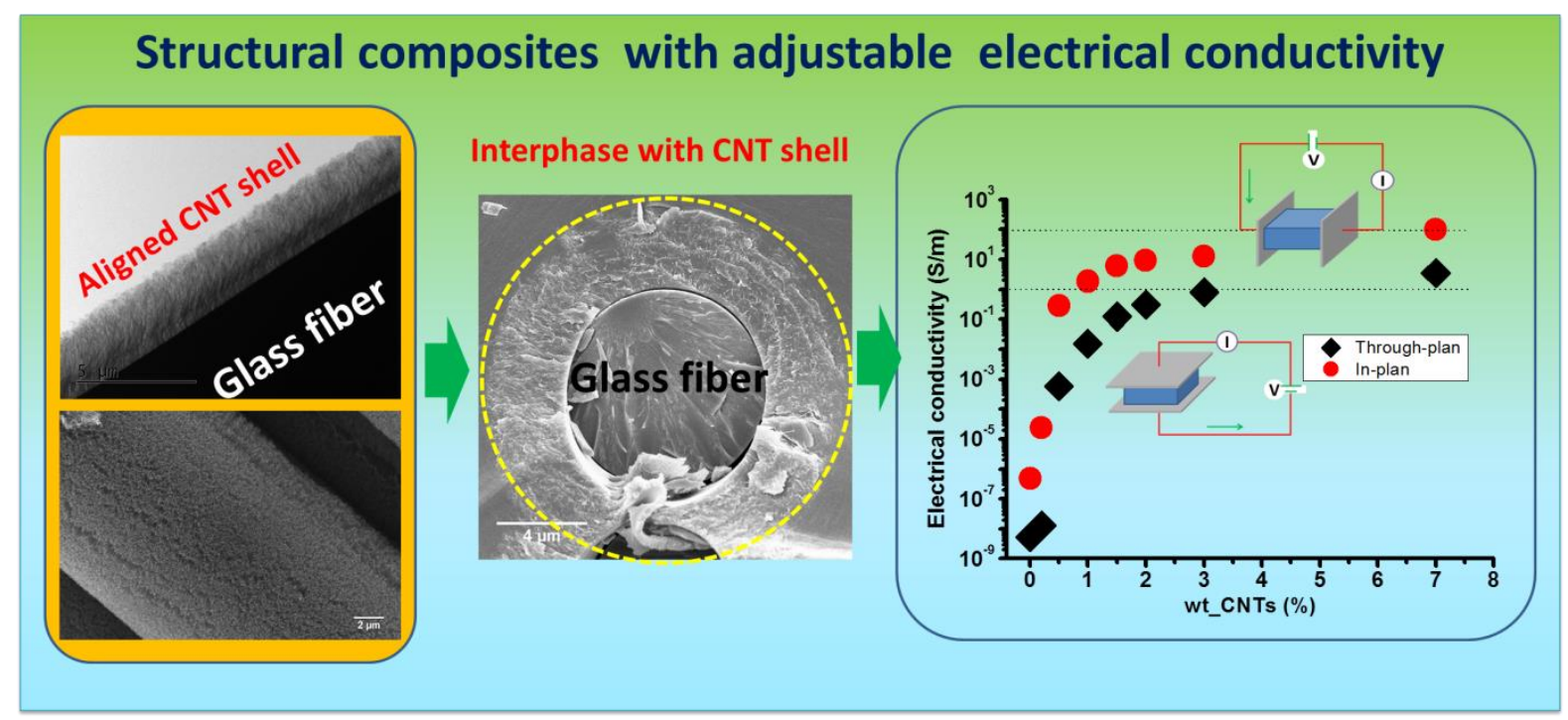

